\title{
Modeling of coupled deformation and permeability evolution during fault reactivation induced by deep underground injection of $\mathrm{CO}_{2}$
}

Frederic Cappa ${ }^{1,2}$ and Jonny Rutqvist ${ }^{1}$

${ }^{1}$ Lawrence Berkeley National Laboratory, Earth Sciences Division, University of California, Berkeley, USA

${ }^{2}$ GeoAzur (UMR6526), University of Nice Sophia-Antipolis, Côte d'Azur Observatory, SophiaAntipolis, France

Corresponding author: Fax (33).4.92.94.26.57

Email adresses: cappa@geoazur.unice.fr (F. Cappa) ; jrutqvist@lbl.gov (J. Rutqvist)

\section{ABSTRACT}

The interaction between mechanical deformation and fluid flow in fault zones gives rise to a host of coupled hydromechanical processes fundamental to fault instability, induced seismicity, and associated fluid migration. In this paper, we discuss these coupled processes in general and describe three modeling approaches that have been considered to analyze fluid flow and stress coupling in fault-instability processes. First, fault hydromechanical models were tested to investigate fault behavior using different mechanical modeling approaches, including slip interface and finite thickness elements with isotropic or anisotropic elasto-plastic constitutive models. The results of this investigation showed that fault hydromechanical behavior can be appropriately represented with the least complex alternative, using a finite thickness element and isotropic plasticity. We utilized this pragmatic approach coupled with a strain-permeability model to study hydromechanical effects on fault instability during deep underground injection of $\mathrm{CO}_{2}$. We demonstrated how such a modeling approach can be applied to determine the likelihood of fault reactivation and to estimate the associated loss of $\mathrm{CO}_{2}$ from the injection zone. It is shown that shearenhanced permeability initiated where the fault intersects the injection zone plays an important role in propagating fault instability and permeability enhancement through the overlying caprock.

\section{Key words :}

Hydromechanical couplings; Fault zone; Numerical simulation; Rupture; Permeability ; Carbone dioxide $\left(\mathrm{CO}_{2}\right)$ 


\section{Introduction}

Hydraulic and mechanical interactions play a critical role in reactivating faults at various scales in the Earth's upper crust (Scholz, 1990). Fault slip may be triggered by changes in the hydraulic pressurization or by tectonic processes. Indeed, stress and fluid pressure conditions in fault zones may induce seismic or aseismic slip at various depths in the seismogenic portion of the crust, and may also potentially control the nucleation, propagation, arrest, and recurrence of moderate to large earthquakes (Hickman et al, 1995; Sibson and Rowland, 2003; Wibberley and Shimamoto, 2005). Key factors in triggering fault slip are shear stress accumulations and fluid pressures, which may facilitate rupture by reducing fault strength. Many studies indicate that rupture can occur in the presence of fluid overpressures on faults optimally or nonoptimally oriented relative to in situ stress fields (Sibson, 1992a-b; Miller et al, 1996; Streit and Cox, 2001; Miller et al, 2004). In general, analysis of fault hydromechanical behavior and quantitative evaluation of changes in material properties during fault slip are rarely if at all conducted. Hydromechanical behavior of fault zones have been mainly studied in research related to geological containment of hydrocarbons (Engelder and Leftwich, 1997; Wiprut and Zoback, 2000), or associated with the so-called fault valve behavior over geological time (Sibson, 1992a-b, 1994, 2007). Faultvalve behavior is described as repeated episodes of shear rupture and hydrothermal sealing, which can lead to cyclic variation in fluid pressure within active faults. Recently, the hydromechanical behavior of fault zones has been investigated to assess the geological risks (i.e., induced seismicity and fluid leakages) related to carbon dioxide $\left(\mathrm{CO}_{2}\right)$ sequestration (Hawkes et al., 2004; Streït and Hillis, 2004; Rutqvist and Tsang, 2005; Rutqvist et al., 2007).

Sequestration of large amounts of $\mathrm{CO}_{2}$ within deep underground reservoirs has been proposed as a potential approach to reducing atmospheric emissions of greenhouse gases. At depths below $800 \mathrm{~m}, \mathrm{CO}_{2}$ is within the range of temperature and pressure conditions favorable to reaching a supercritical phase; having a liquid-like density that provides the potential for efficient use of underground storage in porous sedimentary rocks (Pruess, 2003). Supercritical $\mathrm{CO}_{2}$ is less dense than water and therefore geological containment requires a permeable storage reservoir sealed with a sufficiently low-permeable caprock. Nevertheless, geological systems are heterogeneous and discontinuous media, in which $\mathrm{CO}_{2}$ 
migration could occur through existing fractures and fault zones. For instance, natural $\mathrm{CO}_{2}$ degassing through active fault zones were observed during the 1965-1967 Matsushiro earthquake swarm in Central Japan (Cappa et al., 2009), and the 1997 Umbria-Marche seismic sequence in northern Italy (Miller et al., 2004). For these two seismic events, a pressurized $\mathrm{CO}_{2}$ source has been suggested as the main triggering and driving mechanism for earthquake ruptures. Thus, it is important to assess the potential for seismic events and to estimate how such an event might impact sequestration efficiency (Hawkes et al., 2004, Rutqvist et al., 2007; Chiaramonte et al., 2007; Morris et al., 2009). The impact of faults on fluid flow and geomechanical responses during active $\mathrm{CO}_{2}$ injection has also recently been observed in practice at the In Salah $\mathrm{CO}_{2}$ storage site in Algeria (Ringrose et al., 2009; Vasco et al., 2010).

Fault zones in the Earth's upper crust contain complex structures-generally a fault core and a damage zone-that have distinct mechanical and permeability properties (Vermilye and Scholz, 1998; Gudmundsson, 1999, 2000; Wibberley and Shimamoto, 2003; Faulkner et al., 2003; Cappa et al, 2007; Guglielmi et al., 2008; Mitchell et al., 2009; Cappa, 2009). The fault core is a low-permeability zone with small intergranular porosity, whereas the damage zone is a more permeable zone with a macroscopic fracture network. Depending on host rock lithology as well as fault dimensions and movement, the permeability of the fault zone may vary drastically, making the zone act either as a barrier or as a conduit for fluid flows (Caine et al., 1996). Moreover, the permeability of the fault zone changes during slip and the sudden stress reduction associated with earthquakes (Uehara and Shimamoto, 2004). Field data and models indicate that the core/damage-zone contact often ruptures during earthquakes. Both the core and damage zones grow in thickness with increasing displacement (Vermilye and Scholz, 1998), and fractures that thus open allow fluid flow in those zones. Observations of seismic fault zones exhumed from depth or cored by drill holes show that the width of the damage zone ranges about 10 to $50 \mathrm{~m}$ on both sides of the central fault plane for faults with a single core (Caine et al., 1996; Gudmundsson, 2004; Mitchell and Faulkner, 2008), and at least several hundreds meters and possibly $1-2 \mathrm{~km}$ for major fault zones with multiple cores, like the Punchbowl fault on the San Andreas system (Wilson et al., 2003). Such fault architecture has also been observed in minor faults in argillaceous rocks that are relevant to caprocks at geological $\mathrm{CO}_{2}$ sequestration sites 
(Constantin et al., 2004). In such cases, faults with offsets on the order of a few meters may have a fault core of a few centimeters and a damage zone of several tens of centimeters on each side. However, with respect to $\mathrm{CO}_{2}$ sequestration, both major and minor faults are relevant. Although injection may be located away from known major faults, it is recognized that fluid pressurization from future industrial-scale $\mathrm{CO}_{2}$ injections may affect an area extending to a radius over more than $100 \mathrm{~km}$ (Pruess 2003; Birkholzer and Zhou, 2009). Over such a vast area, some major faults may not be avoidable, and the likelihood and potential consequences of reactivation therefore need to be analyzed.

Permeability and Young's modulus of fault rock have been measured in a large variety of host rocks (mainly sedimentary and metamorphic rocks) by several authors (Fig. 1a-c) (Faulkner and Rutter, 2001; Wibberley and Shimamoto, 2003; Gudmundsson, 2004; Faulkner et al., 2006; Lockner et al., 2009). The permeability of the fault core typically ranges from $1 \times$ $10^{-17}$ to $1 \times 10^{-21} \mathrm{~m}^{2}$ (Fig. $1 \mathrm{~b}$ ) and the Young's modulus ranges from 1 to $10 \mathrm{GPa}$ (Fig. 1c). The areas surrounding the fault core are found to be damaged, intensively fractured, having highly variable properties with permeability ranging from $1 \times 10^{-14}$ to $1 \times 10^{-16} \mathrm{~m}^{2}$, while Young's modulus ranges from 10 to 50 GPa (Gudmundsson, 2004; Faulkner et al., 2006).

To date, generally accepted hydromechanical conceptual models for faults as described above exist, but there is a lack of data regarding the coupled hydromechanical behavior of faults and fault zones. On the other hand, a substantial amount of research has been conducted on the hydromechanical behavior of intact rock, single fractures, and fractured rock (see reviews by Rutqvist and Stephansson, 2003 as well as Tsang et al., 2007). Such research on the fundamental behavior of various rock types is relevant to fault zones, because fault zones are composed of porous rock (the fault core), single-fracture planes, and highly fractured rock (the damaged zone). Thus, a hydromechanical fault-permeability model may be developed based on the fundamental knowledge of the hydromechanical behavior of its various components. Such a model needs to be tested against field observations at a relevant field scale, to assure that the most essential hydraulic and mechanical responses can be realistically simulated. A single-fault hydromechanical model covering all these types of faults and fault stages may not be possible. Alternatively, a more general modeling tool might be developed for analysis of fault slip in various types of faults, at various stages of 
development, in different types of host rock. Furthermore, the approach applied for analysis of coupled hydromechanical fault behavior depends on the scale of interest. At a large regional scale, it might not be possible to represent the fault heterogeneities in detail. We may have to resort to a lumped, representative fault-permeability model that would capture the most relevant aspects of fault hydromechanical behavior at the scale of interest.

In this paper, we analyze different hydromechanical fault reactivation models and demonstrate how such models can be applied as part of a coupled multiphase fluid flow and geomechanical analysis of a $\mathrm{CO}_{2}$ injection site. We apply the TOUGH-FLAC simulator previously applied to both generic and site specific studies involving supercritical $\mathrm{CO}_{2}$ injection, geomechanics, and ground-surface deformations (Rutqvist and Tsang, 2002; Todesco et al., 2004; Rutqvist et al., 2007, 2008, 2009; Cappa et al., 2009). We first provide a general review of the fundamental coupled hydromechanical processes involved in fault instability. Thereafter, the code and various approaches for modeling of coupled hydromechanical processes during fault reactivation are presented and compared with each other. We will show that the least complex alternative model is appropriate, and we demonstrate its use for analyzing fault reactivation and associated permeability during deep underground $\mathrm{CO}_{2}$ injection. We conclude with a discussion of the current status of faultmodel development, providing conclusions based on the detailed results presented in this study.

\section{Fluid pressure/stress coupling and fault instability}

A fault may deform in an irreversible manner (dynamic or progressive rupture) if the shear stress acting on the fault plane is high enough to exceed the shear strength of the fault and induces shear slip (fault reactivation). To estimate the fluid pressures required for the reactivation of faults in rocks-with interconnected pore space under an internal fluid pressure-normal stresses acting on the faults are reduced to effective values according to the effective stress law of Terzaghi (1923):

$\sigma_{n}^{\prime}=\sigma_{n}-P$

where $\sigma_{n}^{\prime}$ is effective normal stress, $\sigma_{n}$ is total normal stress and $P$ is fluid pressure. In failure analysis of a fault with a given orientation, the most fundamental relationship describing 
fault slip, considering hydromechanical interactions, is derived from the effective stress law (Eq. 1) and the Coulomb failure criterion (Jaeger and Cook, 1979), rewritten as:

$$
\tau=c+\mu_{s} \sigma_{n}^{\prime}
$$

where $\tau$ is the critical shear stress for slip occurrence, $c$ is cohesion, and $\mu_{s}$ is the static friction coefficient defined as:

$\mu_{s}=\tan (\varphi)$

where $\varphi$ is the friction angle.

The shear and normal stress acting on the fault plane (Fig. 2a) can be calculated from the two-dimensional principal stresses as:

$$
\begin{aligned}
& \tau=\frac{\left(\sigma_{1}-\sigma_{3}\right)}{2} \sin 2 \delta \\
& \sigma_{n}=\frac{\left(\sigma_{1}+\sigma_{3}\right)}{2}-\frac{\left(\sigma_{1}-\sigma_{3}\right)}{2} \cos 2 \delta
\end{aligned}
$$

where $\sigma_{1}$ is maximum principal stress, $\sigma_{3}$ is minimum principal stress and $\delta$ is the angle between the fault plane and the $\sigma_{1}$ direction (Fig. 2a). The generalization of this type of stress equations to a three-dimensional case (i.e., faults that do not strike parallel to the intermediate principal stress) is not difficult, but the stress transformations required for 3D analyses have been ignored from this paper for the sake of simplicity.

Equations (1) and (2) indicate that increasing fluid pressure may induce shear slip along the fault (Fig. 2b). To accurately estimate the potential for reactivation of faults, both appropriated fluid pressures and stresses need to be constrained. Fault instability is frequently evaluated in terms of the ratio of shear stress to effective normal stress $\left(\tau / \sigma_{n}^{\prime}-\right.$ called "slip tendency" or "ambient stress ratio") acting on the fault plane (Streit and Hillis, 2004). According to Eq. (2), for a well-established, cohesionless fault (c = 0) (note the cohesion may be restored by hydrothermal cementation), slip will be induced once the ambient stress ratio exceeds the coefficient of static friction. For most rocks, $\mu_{s}$ ranges from 0.6 to 0.85 , based on laboratory tests (Byerlee, 1978), borehole stress measurements (Townend and Zoback, 2000), and a range of structural and seismological observations on active faults in the upper seismogenic crust (Collettini and Sibson, 2001). Generally, a frictional coefficient of 0.6 is a lower-limit value observed for the most hydraulically and optimally oriented fault zones active in the upper seismogenic crust (Sibson and Rowland, 
2003). However, $\mu_{s}$ can be lower $\left(\mu_{s}=0.4\right)$ if faults contain clay minerals, or gouge (Wibberley and Shimamoto, 2005).

\section{Development and implementation of a coupled hydromechanical fault-permeability model}

In this section we present the development and implementation of a coupled hydromechanical fault-permeability model into the coupled fluid flow and geomechanical simulator TOUGH-FLAC. As already described in Section 1, permeability structures of faults can be very complex, depending on host rock conditions as well as previous loading history. Faults may be at different stages of development, having different fault architectures, from a single shear plane, or sealed structural porosity, to a mature major fault zone with complex permeability structure, including a core zone and an adjacent fractured damage zone. Thus, while a single fault hydromechanical model cannot cover all types of faults, a general modeling approach may be developed and modified for specific fault architectures.

\subsection{The TOUGH-FLAC simulator}

TOUGH-FLAC (Rutqvist et al., 2002; Rutqvist and Tsang, 2002) is a simulator linking a finite-volume multiphase flow code (TOUGH2-Pruess et al., 1999) and a finite-difference geomechanical code (FLAC ${ }^{3 D}$-Itasca, 2006). In analysis of coupled thermo-hydro-mechanical problems, TOUGH 2 and $\mathrm{FLAC}^{3 \mathrm{D}}$ are executed on compatible numerical grids and linked through external coupling modules, which serve to pass relevant information between the field equations that are solved in the respective codes (Fig. 3). A TOUGH-to-FLAC link takes multiphase pressures, saturation, and temperature from the TOUGH2 simulation and provides the updated temperature and pore-pressure information to $\mathrm{FLAC}^{3 \mathrm{D}}$. After data transfer, $\mathrm{FLAC}^{3 \mathrm{D}}$ internally calculates thermal expansion and effective stress. In a multiphase flow calculation, the value of pressure transferred to $\mathrm{FLAC}^{3 \mathrm{D}}$ represents an average pore pressure-which depends on both liquid and gas pressure $\left(P_{l}\right.$ and $P_{g}$, respectively) as well as liquid saturation $\left(S_{l}\right)$-defined as:

$P=S_{l} P_{l}+\left(1-S_{l}\right) P_{g}$ 
Conversely, a FLAC-to-TOUGH link takes the element stress and deformation from FLAC ${ }^{3 D}$ and updates the corresponding element porosity, permeability, and capillary pressure to be used by TOUGH2. A separate batch program can control the coupling and execution of TOUGH2 and FLAC ${ }^{3 D}$ for the linked TOUGH-FLAC simulator. The calculation is stepped forward in time with the transient thermo-hydraulical analysis initialized in TOUGH2, and at each time step or at the TOUGH2 Newton iteration level, a quasi-static mechanical analysis is conducted with $\mathrm{FLAC}^{3 \mathrm{D}}$ to calculate stress-induced changes in porosity and intrinsic permeability. The resulting thermo-hydro-mechanical analysis may be explicitly sequential, meaning that the porosity and permeability is evaluated only at the beginning of each time step, or implicitly sequential, with permeability and porosity updated on the Newton iteration level towards the end of the time step, using an iterative process.

A coupled hydromechanical fault model can be developed within the framework of TOUGH-FLAC by utilizing existing capabilities within TOUGH2 and $\mathrm{FLAC}^{3 \mathrm{D}}$ codes, and by developing specially designed coupling modules for faults. In a TOUGH-FLAC model, the fault is discretized using special interface and/or solid elements. The coupling functions are then developed for the selected fault representation.

\subsection{Fault modeling approaches}

In general, the mechanical behavior of faults and fault zones can be represented in FLAC $^{3 D}$ by special zero-thickness mechanical interfaces (Fig. 4a), by an equivalent continuum representation using solid elements (Fig. 4b), or by a combination of solid elements and ubiquitous joints oriented as weak planes (Fig 4c).

Figure $4 a$ shows a fault represented by a $\mathrm{FLAC}^{3 \mathrm{D}}$ mechanical interface. An interface can be used to model the mechanical behavior of faults characterized by Coulomb sliding and/or separation. Interfaces have the properties of friction, cohesion, dilation, normal and shear stiffnesses, and tensile strength. An interface can operate in large or small-strain mode. An interface representation is perhaps the most appropriate if the thickness of the fault is negligible compared to the size of the problem. This may include major fault zones in a regional-scale model (on the order of kilometers), or minor shear fractures at a smaller scale. 
To simulate permeability enhancement along the interface, or sealing effects across the interface, TOUGH2 hydraulic elements are added along the interface. The TOUGH2 hydraulic element provides fluid pressure that will act within the fault, affecting the effective normal stress, which in turn affects shear strength (according to the Coulomb criterion).

A finite thickness element reprentation of a fault can be done using $\mathrm{FLAC}^{3 \mathrm{D}}$ standard solid elements (Fig. 4b). In such case, the fault mechanical properties can be represented by constitutive models of various sophistication, from the simplest isotropic linear elastic to more complex elasto-plastic or visco-plastic (creep) models. One particularly interesting approach, available in $\mathrm{FLAC}^{3 \mathrm{D}}$, is to represent the mechanical behavior of the fault as a ubiquitous fractured media to represent strongly anisotropic mechanical behavior (Fig. 4c). The ubiquitous-joint model accounts for the presence of an orientation of weakness (weak plane) in Mohr-Coulomb model. The criterion for failure on the weak planes consists of a composite Mohr-Coulomb envelope with a tension cut-off. A more complex constitutive model is the bilinear strain-hardening/softening ubiquitous joint model. With this model, softening or hardening plastic flow behavior can be modeled for both the weak planes and the intermediate rock matrix. For a single fault plane, the continuum approach shown in Fig. $4 \mathrm{c}$ in combination with a ubiquitous-joint model, could be used to produce the same results as the interface model approach shown in Figure 4a, provided that the same Coulomb shearstrength parameters are used in both cases. The greatest advantage of using solid elements for modeling of faults is the ability to account for cross fault heterogeneity, as well as mechanical interactions between weak planes and intermediate matrix.

\subsection{Permeability couplings for a zero-thickness interface representation of faults}

When zero-thickness interface elements are used to represent a single fault plane, established coupled hydromechanical models for single rock fractures in the field of rock mechanics may be utilized. The hydraulic and mechanical behavior of a single fault plane may be described in terms of flow transmissivity and fracture normal and shear stiffness. Laboratory experiments on single fractures show that fracture transmissivity can be very sensitive to changes in stress normal to the fractures as well as to shear displacement. Thus, 
mechanically induced changes in the fault's ability to conduct fluid may be estimated using the cubic relations between flow along an open fracture and fracture aperture:

$$
T=\frac{b_{h}^{3} \rho g}{12 \mu}
$$

where $T$ is the fault transmissivity and $b_{h}$ is fracture aperture, $\rho$ and $\mu$ are fluid density and viscosity, respectively, and $g$ acceleration of gravity. For a change in aperture caused by mechanical responses, the fault transmissivity should be updated to (Witherspoon et al., 1980):

$T=\frac{\left(b_{h}+\Delta b_{h}\right)^{3} \rho g}{12 \mu}$

In a first order approximation, it may be assumed that the changes in hydraulic aperture $\left(\Delta b_{h}\right)$ are proportional to changes in fracture normal displacement $\left(u_{n}\right)$, i.e.

$\Delta b_{h}=f \cdot \Delta u_{n}$

where $f$ is a friction factor that accounts for the roughness of the fracture surface.

In general, changes in fracture normal displacement may occur as a result of a change in fracture normal stress $\left(\sigma_{n}\right)$, or as a result of dilation during shear deformation $\left(u_{s}\right)$, or by a combination of the two, i.e :

$\Delta u_{n}=\Delta u\left(\Delta \sigma_{n}, \Delta u_{s}\right)$

In $\mathrm{FLAC}^{3 \mathrm{D}}$, the fracture normal displacements within interfaces are calculated as a function of normal stress and shear dilation. Actually, the code calculates the penetration of two neighboring blocks at interface element nodal points. Thus, $\Delta u_{n}$ should be calculated from the changes in interface element penetration, which in turn should be calculated from associated nodal penetrations.

\subsection{Permeability couplings for finite thickness element representation of faults}

Mechanical and hydromechanical properties of fault rock may be anisotropic or isotropic, depending on fault architecture. An isotropic model may be appropriate for analysis of mechanically induced changes in hydraulic properties-for example, in a homogenous, unfractured fault core or in the damaged zone if it is heavily fractured, and without any preferred fracture direction. In such cases, the changes in porosity and 
permeability may be related to changes in mean stress or volumetric strain, which will affect the hydraulic properties equally across and along a fault. Moreover, an isotropic elastoplastic model may be applied to investigate the potential inelastic changes caused by high differential stresses. Although isotropic, plasticity would preferably develop along the already weakened fault, and permeability may be changed based on plastic strain.

In the case of an anisotropic constitutive elasto-plastic model we utilize existing permeability models developed for ubiquitously fractured media (Bai and Elsworth, 1994; Hsiung et al., 2005). The model developed by Hsiung et al. (2005) is attractive in this case, because it was developed and applied for modeling of fractured media using the FLAC ${ }^{3 D}$ ubiquitous joint elasto-plastic model. This approach was tested against field measurements of rock-mass permeability changes induced by thermal stresses in a large-scale, multi-year heater experiment in intensively fractured rocks (Rutqvist et al., 2005).

A permeability change factor is derived based on a nonlinear normal stress-versuspermeability function with the option of plastic strain dilation, according to (Hsiung et al., 2005):

$\frac{k}{k_{i}}=\left[\frac{a}{c\left(c \sigma_{n}^{\prime}+1\right)} \frac{1}{b_{h i}}+\frac{e_{f t p}+e_{f s p} \tan \psi}{f_{d} b_{h i}}\right]^{3}$

where $a$, and $c$ are empirical constants for normal-closure hyperbola, $e_{f t p}$ is the plastic strain caused by tensile failure, $e_{f s p}$ is the plastic shear strain, $b_{h i}$ is the initial fracture aperture, $f_{d}$ is the fracture frequency (1/spacing), and $\psi$ is dilation angle. The above formulation is based on the widely used Bandis' hyperbola for fracture normal closure, with the possibility of investigating shear effects through the shear strain correction.

When using an isotropic elasto-plastic model, we simply relate the permeability to volumetric strain (the sum of the elastic and plastic components of strain) using a model developed and applied by Chin et al. (2000) for modeling of permeability changes in petroleum reservoirs:

$\phi=1-\left(1-\phi_{\mathrm{i}}\right) \mathrm{e}^{-\varepsilon_{\mathrm{v}}}$

$k=k_{i}\left(\frac{\phi}{\phi_{i}}\right)^{n}$ 
where $\phi$ is the porosity at a given stress, $\phi_{i}$ is the initial porosity, $\varepsilon_{v}$ is volumetric strain, $k$ is the permeability at a given stress, $k_{i}$ is the initial permeability, and $n$ is a power-law exponent. Relating the permeability to porosity and volumetric strain (rather than stress) enables consistent permeability correction for both elastic and plastic mechanical behavior. An alternative permeability-porosity relationship includes Carman-Kozeny (Scheidegger, 1974), as well as common empirical exponential relationships (Van-Golf Racht, 1982).

\section{Simulation example of fault slip during $\mathrm{CO}_{2}$ injection}

Here, we present results of a generic simulation of fault slip during $\mathrm{CO}_{2}$ injection in a deep reservoir. We tested the different modeling approaches discussed above in Section 3, which includes the representation using a zero-thickness interface, or using finite thickness solid elements. Then, we conduct a fully coupled hydromechanical analysis to test the sensitivity of the fault hydromechanical behavior to permeability changes induced by fault deformation (opening and slip), considering volumetric strain-dependent permeability change.

\subsection{Model setup}

Figure 5 introduces the geometry and initial conditions of the basic model, which is discretized into a two-dimensional model $(2 \mathrm{~km} \times 2 \mathrm{~km})$. The model extends vertically from $500 \mathrm{~m}$ to $2500 \mathrm{~m}$ depth and horizontally far enough from the injection zone $(2 \mathrm{~km})$ to simulate laterally infinite acting conditions. The horizontal size of the model was chosen from a sensitivity study which indicated that this size does not affect results in the zone of interest. The model consists of a storage aquifer $100 \mathrm{~m}$ in thickness, bounded at bottom and top by a low-permeable 150 m thick caprock, which, in turn, is surrounded by two other aquifers extending vertically $1,650 \mathrm{~m}$ below and 1,350 $\mathrm{m}$ above, respectively. This multilayer system is intersected by a pre-existing normal fault with a dip angle of $80^{\circ}$. When the fault is represented using finite thickness solid elements, the fault width is $10 \mathrm{~m}$. The fault and the injection point are spaced $500 \mathrm{~m}$ horizontally. In this case, we envision a relatively minor fault with an offset of a few to perhaps ten meters, so that the offset will not impact flow behavior within the reservoir itself. The fault architecture may consist of a fault core and 
damaged zone according to Figure 1, but the different components of the fault architecture are not explicitly considered in this simulation study.

In the simulations, $\mathrm{CO}_{2}$ is injected as a point source at $1,500 \mathrm{~m}$ depth with a constant rate of $0.02 \mathrm{~kg} / \mathrm{m} / \mathrm{s}$ (Fig. 5). At this depth, initial fluid pressure and temperature $(P=14.72$ $\mathrm{MPa}$ and $\mathrm{T}=47.5^{\circ} \mathrm{C}$ ) assure supercritical conditions for $\mathrm{CO}_{2}$. The temperature is assumed to be $22.5^{\circ} \mathrm{C}$ at $500 \mathrm{~m}$ depth and $72.5^{\circ} \mathrm{C}$ at $2,500 \mathrm{~m}$, resulting in a depth gradient of $25^{\circ} \mathrm{C} / \mathrm{km}$ and assuming a temperature of $10^{\circ} \mathrm{C}$ on the ground surface. The initial fluid pressure at 500 $\mathrm{m}$ depth is $5 \mathrm{MPa}$ and $24.63 \mathrm{MPa}$ at 2,500 $\mathrm{m}$, considering a hydrostatic gradient $(9.81$ $\mathrm{MPa} / \mathrm{km}$ ) and an atmospheric pressure of $0.1 \mathrm{MPa}$ at the ground surface. Constant pressure, saturation, and temperature conditions are assumed at the boundaries, except for the left boundary, where no flow occurs. That is, the other boundaries are open for fluid flow. Simulations are conducted in an isothermal mode, which implies that the thermal gradient is maintained according to the initial conditions. Null displacement conditions were set normal to the left and bottom boundaries, whereas stress was set to the right and top boundaries. An extensional stress regime $\left(\sigma_{h}=0.7 \sigma_{v}\right)$ was assumed. The model is executed in a plane strain analysis.

Hydraulic and mechanical properties are given in Table 1 for the basic case of fault representation with finite thickness elements using an isotropic elasto-plastic constitutive mechanical model. Properties for the permeable aquifers and the caprocks represent sandstone and shale, respectively. Reservoir rocks are considered to be elastic, whereas the fault follows an elasto-plastic behavior. The fluid-property module ECO2N (Pruess and Spycher, 2007) was employed for modeling the thermodynamic and thermophysical properties of water- $\mathrm{NaCl}-\mathrm{CO}_{2}$ mixtures. The relative permeability of gas and liquid phases is calculated from Corey's function (Corey, 1954), while capillary pressure is governed by the van Genuchten's function (1980).

\subsection{Comparative simulation of different fault modeling approaches}

We examined the sensitivity to fault hydromechanical behavior of different fault model representations and elasto-plastic mechanical models, including the isotropic Mohr-Coulomb 
and the anisotropic ubiquitous Joint models implemented in $\mathrm{FLAC}^{3 \mathrm{D}}$. The basic properties for finite-thickness $(10 \mathrm{~m})$ fault representation and an isotropic elasto-plastic constitutive model are those given in Table 1. The mechanical properties for an anisotropic (ubiquitous joint) elasto-plastic model and the interface elasto-plastic model were chosen to assure consistent effective mechanical properties of the fault. In the case of fault representation with a ubiquitous joint model, we assigned a series of parallel weak planes with a dip angle of $80^{\circ}$ and a spacing of $0.2 \mathrm{~m}$ within the fault. Weak planes were assumed to have a normal and shear stiffness of $5 \mathrm{GPa} / \mathrm{m}$, and were assumed to be cohesionless, with a friction angle of $25^{\circ}$, a dilation angle of $20^{\circ}$ and no tensile strength. In the case of interface representation, we assigned same Mohr-Coulomb properties (friction angle of $25^{\circ}$, a dilation angle of $20^{\circ}$ ) and equivalent fracture normal stiffness and shear stiffness.

Modeling results presented in Figure 6, for 5-years of $\mathrm{CO}_{2}$ injection, show almost identical results for the three modeling approaches. Pressures, stresses and displacements along the fault follow the same paths with equivalent magnitudes. Pressure substantially increases $\left(\Delta \mathrm{P}_{\max }=15 \mathrm{MPa}\right)$ at the fault section located in the $\mathrm{CO}_{2}$ storage reservoir and in the upper and basal caprocks, with the rest of the fault remaining at hydrostatic pressure. The effective normal stress decreases $\left(\Delta \sigma^{\prime}{ }_{\text {Mmax }} \sim-9 \mathrm{MPa}\right)$, whereas the total stress increases $\left(\Delta \sigma_{\mathrm{Nmax}} \sim 7 \mathrm{MPa}\right)$. Along the fault, the shear stress decreases (i.e. stress drop) in the fault section located in the storage reservoir and in the caprocks $\left(\Delta \tau_{\max } \sim 1.75 \mathrm{MPa}\right)$. Shear slip increases in the same fault section, with a maximal magnitude of $0.25 \mathrm{~m}$.

This model comparison shows that for equivalent mechanical properties, each approach can accurately simulate fault hydromechanical behavior, at least when no permeability changes are assumed. We then select the least complex finite-thickness-element model with the isotropic elasto-plastic constitutive mechanical model for the two-way coupled hydromechanical analysis presented in the next section.

\subsection{Simulation of fault instability and permeability change}

Figures 7 to 9 present the results from an analysis of fault hydromechanical response to permeability changes during $\mathrm{CO}_{2}$ injection. In this simulation, the fault zone was assumed to 
have isotropy of mechanical and hydraulic properties as in the previous model setup (Fig. 4b and 5; Table 1). For simulating permeability changes, we applied the relationships in Equations 12 and 13 for correcting permeability with volumetric strain. In Chin et al. (2000), a value of $n$ equal to 5.6 was determined to fit permeability and porosity changes for experimental data in highly permeable sandstones. In the present study, we use a value of 15 for $n$ to simulate the effects of a permeability increase of about 1 to 2 orders of magnitude in the fault zone.

The initial fault permeability was set to $k_{i}=1 \times 10^{-16} \mathrm{~m}^{2}$-reasonable considering field and laboratory data on faults (Wibberley and Shimamoto, 2003; Townend and Zoback, 2000; Talwani and Acree, 1984). This permeability value represents a lower limit value of permeability within the damaged zone of a typical fault (see Figure 1). This zone, which includes increased fracturing, has a permeability of about 3 orders of magnitude higher than that for the surrounding shale caprock. Thus, some fluid may penetrate the fault, which in turn may trigger fault reactivation. We assume that the fault reactivation can increase the permeability by 1 to 2 orders of magnitude, taking the damaged-zone permeability towards the upper limit $\left(\mathrm{k}=1 \times 10^{-14} \mathrm{~m}^{2}\right)$ given in Figure 1 . For the isotropic plasticity model, we envision the elasto-plastic response within the fault damaged zone is shear failure induced along fractures within the intensively fractured fault damage zone. The plastic shear strain is associated with shear dilation, causing the volumetric strain and permeability to increase. In the injection zone itself, the initial equivalent permeability of the fault $\left(\mathrm{k}=1 \times 10^{-16} \mathrm{~m}^{2}\right)$ is about 3 orders of magnitude lower than the surrounding sandstone $\left(k=1 \times 10^{-13} \mathrm{~m}^{2}\right)$. Thus, the fault acts as a partial flow barrier within the reservoir, but a conduit through the caprock.

In Figure 7, we compare the pressure evolution at the injection point and into the fault after five years of $\mathrm{CO}_{2}$ injection. At the injection point, pressure increases during 6 months, and then reaches a quasi-steady state at $27 \mathrm{MPa}$. After 1.3 years of injection, pressure progressively decreases and reaches $24 \mathrm{MPa}$ after five years of injection. At the injection point, gas saturation increases quickly at the start-up of injection (from 0 to $\sim 0.4$ ) and then continuously increases at a slower rate until the end of injection to reach a value of 0.68 (Fig. 7a). When comparing these results to the simulation results without permeability change 
shown in Figure 6, we note that the pressure increases much less in this case, as a result of reactivation of the fault effectively breaking the partial flow barrier.

At the inlet and outlet of the fault in the upper caprock, pressure changes are sensitive to gas saturation. First, pressure increases during the first six months of injection, and then remains at about 23-24 MPa until 1.2 years of injection. Then, figures $7 \mathrm{~b}-\mathrm{c}$ show that accelerated inflow and increased pressure into the fault occur when gas saturation abruptly increases at the inlet in the upper caprock. In the fault, the increase in gas saturation is faster than that of fluid pressure (Fig. 7b), because $\mathrm{CO}_{2}$ is much less viscous than brine, and therefore its mobility increases as $\mathrm{CO}_{2}$ saturation increases. $\mathrm{CO}_{2}$ spreads quickly through the fault until reaching a steady state gas saturation; $\mathrm{CO}_{2}$ begins at this time to accumulate primarily in the storage aquifer, with a negligible amount accumulating in the caprock and null amount at the fault outlet.

Results also indicate that fault behavior is sensitive to porosity and permeability changes, and that an increase in permeability of about 1-to-1.5 order-of-magnitude tends to significantly increase fault slip $\left(u_{s}=0.115 \mathrm{~m}\right.$ ) (Fig. 8). Fault slip strongly increases both inside and outside the pressurized $\mathrm{CO}_{2}$ storage zone, where pressure increase is lower than in a model without permeability changes (see Section 4.2 for comparison), owing to fault permeability changes in response to mechanical changes. It is clear from Figure 8 , that permeability changes in the fault after 1 year are strongly correlated with fault slip magnitude, which indicates that permeability changes are caused by the volumetric strain associated with shear strain dilation. At 1 month, the permeability changes are small and caused by pressure-induced elastic expansion of the fault rock before the fault is reactivated with shear failure.

Figure 9 shows that $\mathrm{CO}_{2}$ spreads within the storage formation, both upward and laterally, as significant flow is allowed through the fault. Specifically, the largest changes in gas saturation occur in the mid- and upper part of the aquifer, as well as in the fault through the upper caprock. The $\mathrm{CO}_{2}$ spreads from the injection point to the bottom part of the upper caprock in about 2 years, with a lateral diffusion reaching the fault. The $\mathrm{CO}_{2}$ began to reach and migrate up along the fault before the second year of injection, and escape the fault 
towards ground surface after 10 years. Modeling of the interaction of this $\mathrm{CO}_{2}$ with shallower aquitards was not considered in this work.

\section{Concluding remarks}

In this paper, we analyzed different hydromechanical fault reactivation models and demonstrated how such models can be applied to a coupled multiphase fluid flow and geomechanical analysis of a $\mathrm{CO}_{2}$ injection site. We conclude as follows:

(1) The comparative simulation study of different fault modeling approaches has shown that, whether a fault or fault zone is represented by a mechanical interface or by finite thickness solid elements, the overall elasto-plastic behavior is the same.

(2) Our analysis thus showed that the least complex approach tested, using a finite thickness element representation of the fault is appropriate for simulating fluid-pressure-induced fault geomechanical reactivation. A finite thickness element approach is easier to implement and can be readily applied to different kinds of fault architecture, from a single slip plane to a complex fault zone.

(3) The application of this less complex modeling approach to fault reactivation and associated permeability change during a hypothetical $\mathrm{CO}_{2}$ injection operation demonstrated the importance of capturing mechanically induced permeability changes in the fault rupturing processes: Shear-induced permeability enhancement facilitates the propagation of the rupture zone across the overlying caprock.

(4) The simulated fault reactivation and associated permeability enhancement resulted in a $13 \%$ increase in rate of $\mathrm{CO}_{2}$ escaping from the primary storage zone. The amount of $\mathrm{CO}_{2}$ that escaped from the primary storage zone is still only about $1 \%$ of the total volume injected after 15 years. Thus, the simulated fault reactivation can be viewed as an aseismic gradual straining of the fault, resulting in an increased total transmissivity through the upper cap that could reduce the efficiency of the sequestration operation. 
In general, fluid pressure/stress coupling and slip on faults have strong implications for seismicity in the Earth's crust, and are viewed as a likely scenario for generation of possible leakage paths for $\mathrm{CO}_{2}$ sequestration. Our model simulations indicated that a less complex modeling approach, using finite thickness fault representation, was adequate for simulating fluid-pressure-induced fault reactivation. Using this model approach we then simulated permeability changes during reactivation using a simple correction with volumetric strain and a parameter $n=15$, calibrated to achieve a permeability enhancement of 1 to 2 order of magnitude. We acknowledge that we have not conducted a conclusive comparison of the different approaches for fault permeability change. However, a detailed comparison of modeling approaches for permeability change would require a very detailed description of fault architecture and could perhaps be done for very simplistic cases, for example assuming fractures oriented along the main fault orientation with a fixed spacing. For the current study, the use of other approaches would also involve a calibration of parameters to achieve a 1 to 2 order of magnitude permeability change and a comparison may therefore not be meaningful. We acknowledge the uncertainty in the prediction of permeability changes during fault reactivation and that it is strongly dependent on the type of fault and its architecture.

Consequently, further research is needed for a realistic modeling of complex fault structures and for modeling of potential changes in fault permeability and mechanical properties. Shear tests on single fractures in shale indicate that permeability can increase or decrease depending on the current stress normal to the fractures (Gutierrez et al., 2000, Crawford et al., 2002). At high normal stresses, shear slip is accompanied with significant gouge production, and the permeability can actually decrease by several orders of magnitude. However, geological studies indicate that local stresses and the presence of faults control containment and release of deep overpressured fluids. As discussed in Section 1 , a fault can be very heterogeneous, with large variation in permeability and mechanical properties, both along and across the fault. Such heterogeneity may be very important to represent, especially if the problem of interest is in the vicinity of a major fault zone. Crossfault heterogeneous properties could be readily modeled by representing the fault with a number of parallel solid elements, which can have distinctly different properties in the fault core and the adjacent fractured zone. The approach developed and tested in this paper can be readily applied to such a scenario. 


\section{Acknowledgments}

The work presented in this paper was financed by the Ministry of Economy, Trade and Industry Ministry (METI) of Japan. Further funds for completing this paper were provided by the Assistant Secretary for Fossil Energy, Office of Natural Gas and Petroleum Technology, through the National Energy Technology Laboratory, under the U.S. Department of Energy Contract No. DE-AC02-05CH11231. Technical and editorial reviews by Alberto Mazzoldi and Dan Hawkes, Lawrence Berkeley National Laboratory are greatly appreciated. We are grateful for the constructive comments and recommendations of the two anonymous reviewers, which substantially improved this paper.

\section{References}

Bai, M., Elsworth, D., 1994. Modeling of subsidence and strain-dependent hydraulic conductivity for intact and fractured porous media. Rock Mech. Rock Eng., 27: 209-250.

Birkholzer, J.T., Zhou, Q., 2009. Basin-scale hydrogeologic impacts of CO2 storage: Capacity and regulatory implications. Int. J. Greenhouse Gas Control, 3, 745-756.

Byerlee, J.D, 1978. Friction of rocks, Pure Appl Geophys, 116, 615-626.

Caine, J.S, Evans, J.P., Foster, C.G., 1996. Fault zone architecture and permeability structures, Geology, 24(11):1025-1028.

Cappa, F., Guglielmi, Y., Virieux, J., 2007. Stress and fluid transfer in a fault zone due to overpressures in the seismogenic crust, Geophys. Res. Lett., 34, L05301, doi:10.1029/2006GL028980.

Cappa, F., 2009. Modelling fluid transfer and slip in a fault zone when integrating heterogeneous hydromechanical characteristics in its internal structure, Geophys. J. Int. 178, 1357-1362doi: 10.1111/j.1365-246X.2009.04291.x

Cappa, F., Rutqvist, J., Yamamoto, K., 2009. Modeling crustal deformation and rupture processes related to upwelling of deep $\mathrm{CO}_{2}$-rich fluids during the 1965-1967 Matsushiro earthquake swarm in Japan, J. Geophys. Res. 114, B10304, doi:10.1029/2009JB006398. 
Chiaramonte, L., Zoback, M.D., Friedman, S.J., Stamp, V., 2007. Seal integrity and feasibility of $\mathrm{CO}_{2}$ sequestration in the Teapot Dome EOR pilot: geomechanical site characterization, Env. Geol., 1667-1675.

Chin, L.Y, Raghavan, R., Thomas, L.K, 2000. Fully Coupled Geomechanics and Fluid-Flow Analysis of Wells with Stress-dependent Permeability. SPE Journal 5 (1) Paper 58968, 3245.

Collettini, C., Sibson, R.H., 2001. Normal faults, normal friction?, Geology, 29, 927-930.

Constantin, J., Peyaud, J.B., Vergély, P., Pagel, M., Cabrera, J., 2004. Evolution of structural fault permeability in argillaceous rocks in a polyphased tectonic context. Physics and Chemistry of the Earth, 29, 25-41.

Corey A.T., 1954. The interrelation between oil and gas relative permeabilities, Producers Monthly, 38-41.

Crawford, B.R., Myers, R.D, Woronow, A., Faulkner, D.R., Rutter, E.H., 2002, Porositypermeability relationships in clay-bearing fault gouge, SPE/ISRM 78214, 1-13.

Engelder, T., Leftwich, J.T., 1997. A pore-pressure limit in overpressured South Texas oil and gas field, In R.C. Surdam, ed., Seals, traps, and the petroleum system: AAPG Memoir 67, Chapter 15, 255-267.

Faulkner, D.R, Rutter, E.H., 2001. Can the maintenance of overpressured fluids in large strikeslip fault zones explain the apparent weakness ? Geology, 29(6):503-506.

Faulkner, D. R., Lewis, A. C., Rutter, E. H., 2003. On the internal structure and mechanics of large strike-slip faults: Field observations from the Carboneras fault, southeastern Spain, Tectonophys, 367, 235-251.

Faulkner, D.R., Mitchell, T.M., Healy, D., Heap, M., 2006. Slip on 'weak' faults by the rotation of regional stress in the fracture damage zone, Nature, 444(7121), 922-925.

Gudmundsson, A., 1999. Fluid overpressure and stress drop in fault zones, Geophys. Res. Lett., 26(1):115-118

Gudmundsson, A., 2000. Active fault zones and groundwater flow, Geophys. Res. Lett., 27(18):2993-2996

Gudmundsson, A., 2004. Effects of Young's modulus on fault displacement, CR. Geosci., 336, 85-92.

Guglielmi Y., Cappa, F., Amitrano, D., 2008. High-definition analysis of fluid-induced seismicity related to the mesoscale hydromechanical properties of a fault zone, Geophys. Res. Lett., 35, L06306, doi:10.1029/2007GL033087.

Gutierrez, M., Oino, L.E., Nygard, R., 2000. Stress-dependent permeability of a demineralised fracture in shale. Marine and Petroleum Geology, 17, 895-907. 
Hawkes, C.D., McLellan, P.J., Zimmer, U., Bachu, S., 2004. Geomechanical Factors Affecting Geological Storage of $\mathrm{CO} 2$ in Depleted Oil and Gas Reservoirs: Risks and Mechanisms, Proceedings of Gulf Rocks 2004, the 6th North America Rock Mechanics Symposium (NARMS): Rock Mechanics Across Borders and Disciplines, Houston, Texas, June 5-9, Paper 2004-258.

Hawkes, C.D., Bachu, S., Haug, K., Thompson, A.W., 2005. Analysis of in-situ stress regime in the Alberta Basin, Canada, for performance assessment of $\mathrm{CO}_{2}$ geological sequestration sites. Proceedings of the fourth annual conference on carbon capture and sequestration DOE/NETL, May 2-5, 1-22.

Hickman, S., Sibson, R.H., Bruhn, R., 1995. Introduction to special section: mechanical involvement of fluids in faulting, J Geophys Res, 100, 12831-12840.

Hsiung S.M., Chowdhury A.H., Nataraja M.S., 2005. Numerical simulation of thermalmechanical processes observed at the Drift-Scale Heater Test at Yucca Mountain, Nevada, USA. Int. J. Rock. Mech. Min. Sci., 42:652-666.

Itasca Consulting Group, 2006. FLAC ${ }^{3 \mathrm{D}}$, Fast Lagrangian Analysis of Continua in 3 Dimensions. Version 3.0. Five volumes. Minneapolis, Minnesota: Itasca Consulting Group.

Jaeger, J.C, Cook, N.G.W., 1979. Fundamentals of rock mechanics, ed. Third edition. New York: Capman 1 Hall, p. 28-30

Leverett, M. C., 1941. Capillary behavior in porous media, Trans. AIME, 142: 341-358.

Lockner, D.A., Tanaka, H., Ito, H., Ikeda, R., Omura, K., Naka, H., 2009. Geometry of the Nojima fault at Nojima-Hirabayashi, Japan-I. A simple damage structure inferred from borehole core permeability. Pure Appl. Geophys., 166, 1649-1667.

Miller, S.A., Nur, A., Olgaard, D.L, 1996. Earthquakes as a coupled shear stress-high pore pressure dynamical system, Geophys Res Lett, 23, 197-200.

Miller, S.A., Collettini, C., Chiaraluce, L., Cocco, M., Barchi, M., Kaus, B.J.P., 2004. Aftershocks driven by a high-pressure CO2 source at depth, Nature, 427, 724-727

Mitchell, T.M., Faulkner, D.R., 2008, Experimental measurements of permeability evolution during triaxial compression of initially intact crystalline rocks and implications for fluid flow in fault zones, J. Geophys. Res., 113, B11412, doi:10.1029/2008JB005588.

Mitchell, T.M., Faulkner, D.R., 2009. The nature and origin of off-fault damage surrounding strike-slip fault zones with a wide range of displacements: a field study from the Atacama fault system, northern Chile, J. Struct. Geol., 31, 802-816, doi:10.1016/j.jsg.2009.05.002.

Morris, J.P., Detwiler, R.L., Friedman, S.J., Vorobiev, O.Y., Hao, Y., 2009, The large-scale effects of multiple $\mathrm{CO}_{2}$ injection sites on formation stability, Energy Procedia, 1(1):18311837.

Pruess, K., Oldenburg, C., Moridis, G., 1999. TOUGH2 user's guide, version 2.0, Lawrence Berkeley National Laboratory Report, LBNL-43134, Berkeley, p.198. 
Pruess, K., 2003. Numerical simulation of leakage from a geologic disposal reservoir for $\mathrm{CO} 2$, with transitions between super- and sub-critical conditions, Proceedings, TOUGH Symposium 2003 Lawrence Berkeley National Laboratory, Berkeley, California, May 1214, p. 8.

Pruess, K., Spycher, N., 2007. ECO2N - A fluid property module for the TOUGH2 code for studies of $\mathrm{CO} 2$ storage in saline aquifers, Energ. Conv. Man., doi:10.1016/j.enconman.2007.01.016.

Ringrose, P., Atbi, M., Mason, D., Espinassous, M., Myhrer, $\varnothing$, Iding, M., Mathieson, A., Wright, I., 2009. Plume development around well KB-502 at the In Salah CO2 storage site. First Break, 27, 85-89.

Rutqvist, J., Wu, Y-S., Tsang, C-F., Bodvarsson, G., 2002. A modeling approach for analysis of coupled multiphase fluid flow, heat transfer, and deformation in fractured porous rock, Int J Rock Mech Min Sci, 39:429-442.

Rutqvist, J., Tsang, C.-F, 2002. A study of caprock hydromechanical changes associated with $\mathrm{CO}_{2}$ injection into a brine aquifer, Environmental Geology, 42:296-305.

Rutqvist, J., Stephansson, O., 2003. The role of hydromechanical coupling in fractured rock engineering. Hydrogeology Journal, 11, 7-40, doi: 10.1007/s10040-002-0241-5.

Rutqvist, J., Tsang, C.-F., 2005. Coupled hydromechanical effects of $\mathrm{CO}_{2}$ injection, In: Tsang C.F., Apps J.A., editors. Underground Injection Science and Technology. Elsevier, 649679. 26.

Rutqvist, J., Bar,r D., Datta, R., Gens, A., Millard, M., Olivella, S., Tsang, C.-F., 2005. Coupled thermal-hydrological-mechanical analysis of the Yucca Mountain Drift Scale Test comparison of field results to predictions of four different models. Int. J. Rock Mech. \& Min. Sci, 42, 680-697.

Rutqvist, J., Birkholzer, J.T., F. Cappa, Tsang, C-F., 2007. Estimating maximum Sustainable injection pressure during geological sequestration of $\mathrm{CO}_{2}$ using coupled fluid flow and geomechanical fault-slip analysis, Energy Conv. Man., 47, 1798-1807.

Rutqvist, J., Birkholzer, J.T., Tsang C-F., 2008. Coupled reservoir-geomechanical analysis of the potential for tensile and shear failure associated with $\mathrm{CO}_{2}$ injection in multilayered reservoir-caprock systems, Int. J. Rock Mech. Min. Sci., 45, 132-143.

Rutqvist, J., Vasco D.W., Myer, L., 2009. Coupled reservoir-geomechanical analysis of CO2 injection and ground deformations at In Salah, Algeria, Int. J. Greenhouse Gas Control, doi:10.1016/j.ijggc.2009.10.017, in press.

Scholz, C-H., 1990. The mechanics of Earthquakes and faulting. Cambridge University Press, New York.

Scheidegger, A.E., 1974. The physics of flow through porous media. University of Toronto Press, Toronto. 
Sibson, R.H., 1992a. Fault-valve behavior and the hydrostatic-lithostatic fluid pressure interface, Earth-Sci. Rev., Metamorphic Fluids, 32(1-2), 141-144

Sibson, R.H., 1992b. Implications of fault-valve behavior for rupture nucleation and recurrence, Tectonophysics, 211, 283-293.

Sibson, R.H., 1994. Crustal stress, faulting and fluid flow, Geol. Soc., Lond., Special Publ., 78, 69-84.

Sibson, R.H., Rowland, J.V., 2003. Stress, fluid pressure and structural permeability in seismogenic crust, North Island, New Zealand, Geophys. J. Int., 154, 584-594.

Sibson, R.H., 2007. An episode of fault-valve behaviour during compressional inversion? The 2004 M,6.8 Mid-Niigata Prefecture, Japan, earthquake sequence, Earth and Planetary Science Letters, 257, 188-199.

Streit, J.E., Cox, S.F., 2001. Fluid pressures at hypocenters of moderate to large earthquakes. J. Geophys Res, 106, 2235-2243.

Streit, J.E., Hillis, R.R., 2004. Estimating fault stability and sustainable fluid pressures for underground storage of $\mathrm{CO}_{2}$ in porous rock, Energy, 29:1445-1456.

Talwani, P., Acree, S., 1984. Pore pressure diffusion and the mechanism of reservoir-induced seismicity, Pageophys, 122, 947-965.

Terzaghi, K., 1923. Die Berechning der Durchlässigkeitziffer des Tonesaus dem Verlauf Spannungserscheinungen, Akad. Der Wissenchafen in Wien, Sitzungsberichte, Mathematisch-naturwissenschafttliche Klasse, Part lia, 142(3/4), 125-138.

Todesco, M., Rutqvist, J., Chiodini, G., Pruess, K., Oldenburg, C.M., 2004. Modeling of recent volcanic episodes at Phlegrean Fields (Italy): geochemical variations and ground deformation. Geothermics 33, 531-547.

Townend, J., Zoback, M.D., 2000. How faulting keeps the crust strong, Geology, 28, 399-402.

Tsang, C.F, Rutqvist, J., Min, K.B., 2007. Fractured rock hydromechanics: from borehole testing to solute transport and $\mathrm{CO}_{2}$ strorage. Geological Society, London, Special Publications, 284, 15-34, doi:10.1144/SP284.2.

Uehara, S.I., Shimamoto, T., 2004. Gas permeability evolution of cataclasite and fault gouge in triaxial compression and implications for changes in fault-zone permeability structure through the earthquake cycle, Tectonophysics, 378:183-195.

van Genuchten, M.T., 1980. A closed-form equation for predicting the hydraulic conductivity of unsaturated soils, Soil. Sci. Soc. Am. J., 44:892-898.

Van-Golf Racht, T.D., 1982. Fundamentals of fractured reservoir engineering. Elsevier, Amsterdam. 
Vasco, D.W., Rucci, A., Ferretti, A., Novali, F., Bissell, R., Ringrose, P., Mathieson, A., Wright, I., 2010, submitted. Satillite-based measurements of surface deformation reveal fluid flow associated with the geological storage of carbon dioxide. Geophy. Rese. Lett., 37, L03303, doi:10.1029/2009GL041544,

Vermilye, J.M., Scholz, C.H., 1998. The process zone: a microstructural view of fault growth, J. Geophys. Res., 103(B6), 12 223-12 237.

Wibberley, C.A.J., Shimamoto, T., 2003. Internal structure and permeability of a major strickslip fault zones: The Median Tectonic Line in Mie Prefecture, Southwest Japan, J Struct Geol, 25:59-78.

Wibberley, C.A.J., Shimamoto, T., 2005. Earthquake slip weakening and asperities explained by thermal pressurization, Nature, 436:689-692. doi:10.1038/nature03901.

Wiprut, D., Zoback, M., 2000. Fault reactivation and fluid flow along previously dormant normal fault in the North Sea, Geology, 28:595-598.

Wilson, J.E., Chester, J.S. \& Chester, F.M., 2003. Microfracture analysis of fault growth and wear processes, Punchbowl Fault, San Andreas System, California, J. Struct. Geol., 25(11), 1855-1873.

Witherspoon P.A., Wang J.S.Y, Iwai K., Gale J.E., 1980. Validity of Cubic Law for Fluid Flow in a Deformable Rock Fracture, Water Resources Research, 16:1016-1024. 
Table 1. Material properties used to simulate $\mathrm{CO}_{2}$ injection in a faulted reservoir-caprock system. Note that the permeability is expressed in $\mathrm{m}^{2}\left(1 \times 10^{-15} \mathrm{~m}^{2}\right.$ is approximately equal to 1 millidarcy).

\begin{tabular}{llllll}
\hline Parameters & Storage Aquifer & Caprock & Upper Aquifer & Basal Aquifer & Fault \\
\hline Young's modulus, E (GPa) & 10 & 10 & 10 & 10 & 5 \\
Poisson's ratio, $v(-)$ & 0.25 & 0.25 & 0.25 & 0.25 & 0.25 \\
Rock density, $\rho_{s}\left(\mathrm{~kg} / \mathrm{m}^{3}\right)$ & 2260 & 2260 & 2260 & 2260 & 2260 \\
Biot's coefficient, $\alpha(-)$ & 1 & 1 & 1 & 1 & 1 \\
Friction angle, $\varphi\left(^{\circ}\right)$ & - & - & - & - & 25 \\
Dilation angle, $\psi\left({ }^{\circ}\right)$ & - & - & - & - & 20 \\
Porosity, $\phi(-)$ & 0.1 & 0.01 & 0.1 & 0.01 & 0.1 \\
Permeability, $k\left(\mathrm{~m}^{2}\right)$ & $1 \times 10^{-13}$ & $1 \times 10^{-19}$ & $1 \times 10^{-14}$ & $1 \times 10^{-16}$ & $1 \times 10^{-16}$ \\
Residual gas $\left(\mathrm{CO}_{2}\right)$ saturation $(-)$ & 0.05 & 0.05 & 0.05 & 0.05 & 0.05 \\
Residual liquid saturation $(-)$ & 0.3 & 0.3 & 0.3 & 0.3 & 0.3 \\
van Genuchten $(1980), P_{0}(\mathrm{kPa})$ & 19.9 & 621 & 19.9 & 621 & 19.9 \\
van Genuchten $(1980), m(-)$ & 0.457 & 0.457 & 0.457 & 0.457 & 0.457 \\
\hline
\end{tabular}



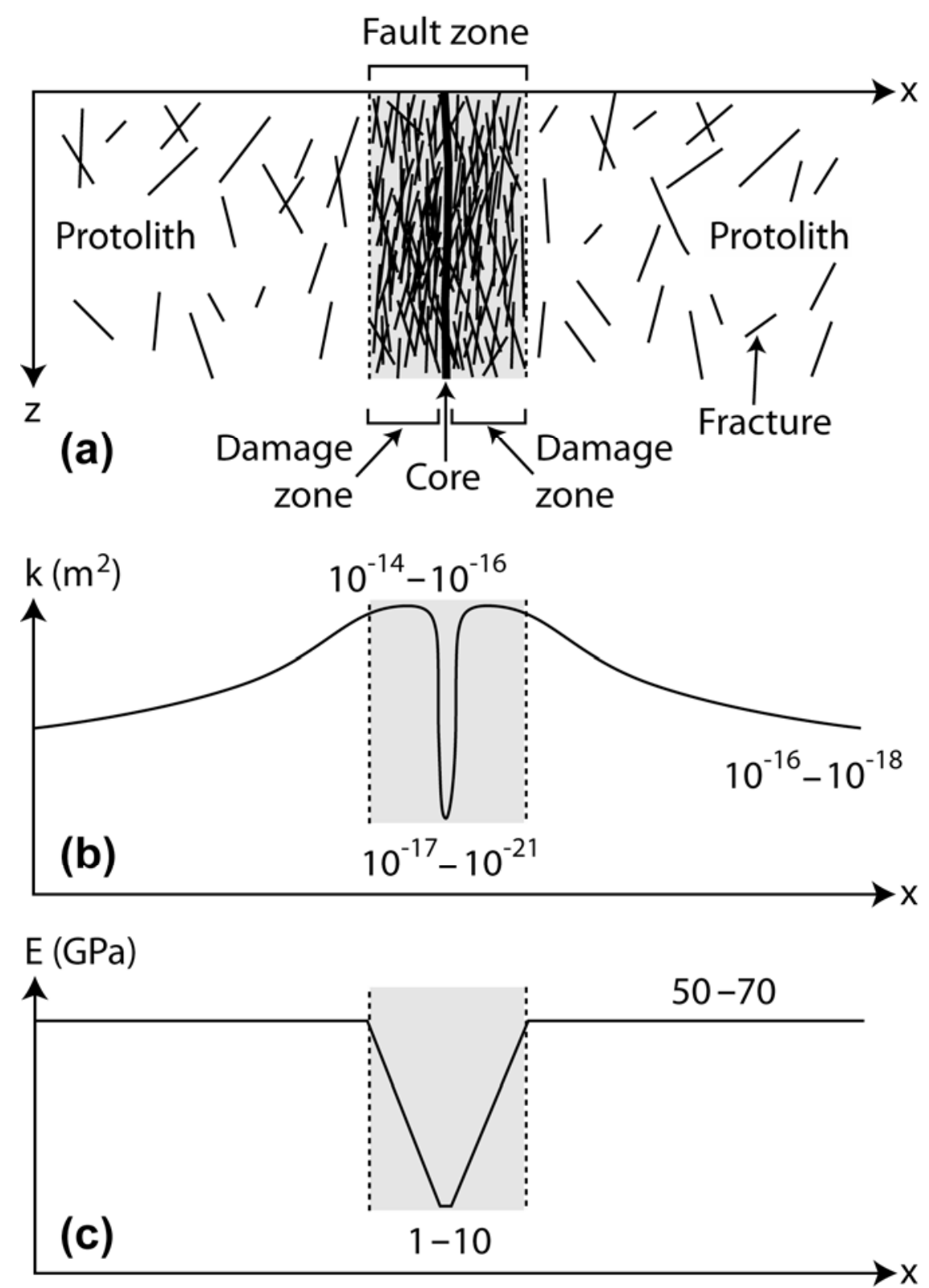

Figure 1. (a) Schematic diagram of the structure across a fault zone and conceptual model of the distribution of (b) permeability and (c) Young's modulus. 
(a)

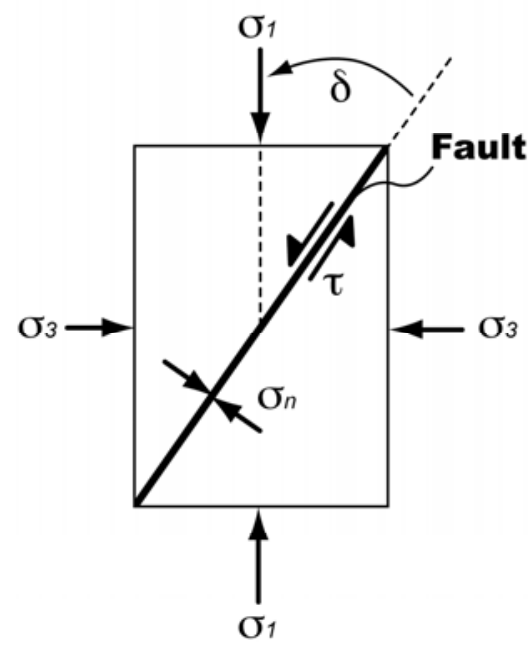

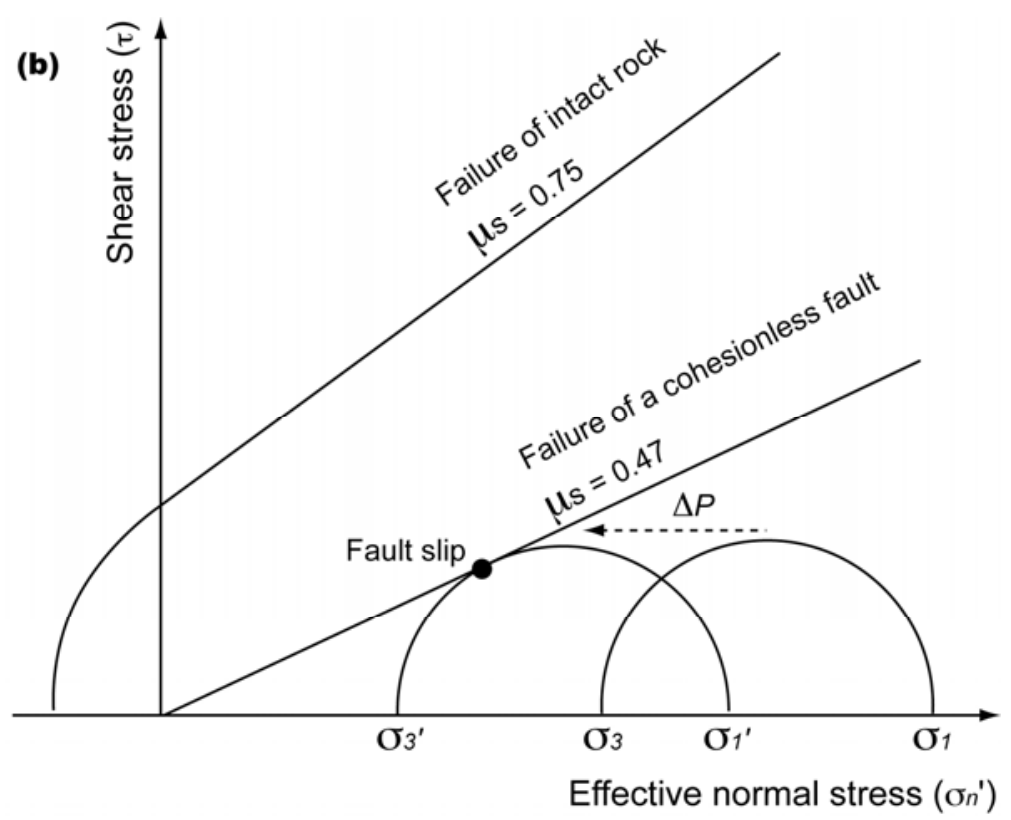

Figure 2. (a) Normal and shear stresses resolved on a fault with a given orientation from the remote principal stresses; (b) Mohr diagram of shear stress $(\tau)$ versus effective normal stress $\left(\sigma_{n}{ }^{\prime}\right)$ showing how the increasing fluid pressure $(\Delta P)$ may activate a well-oriented, cohesionless fault (fault slip). 


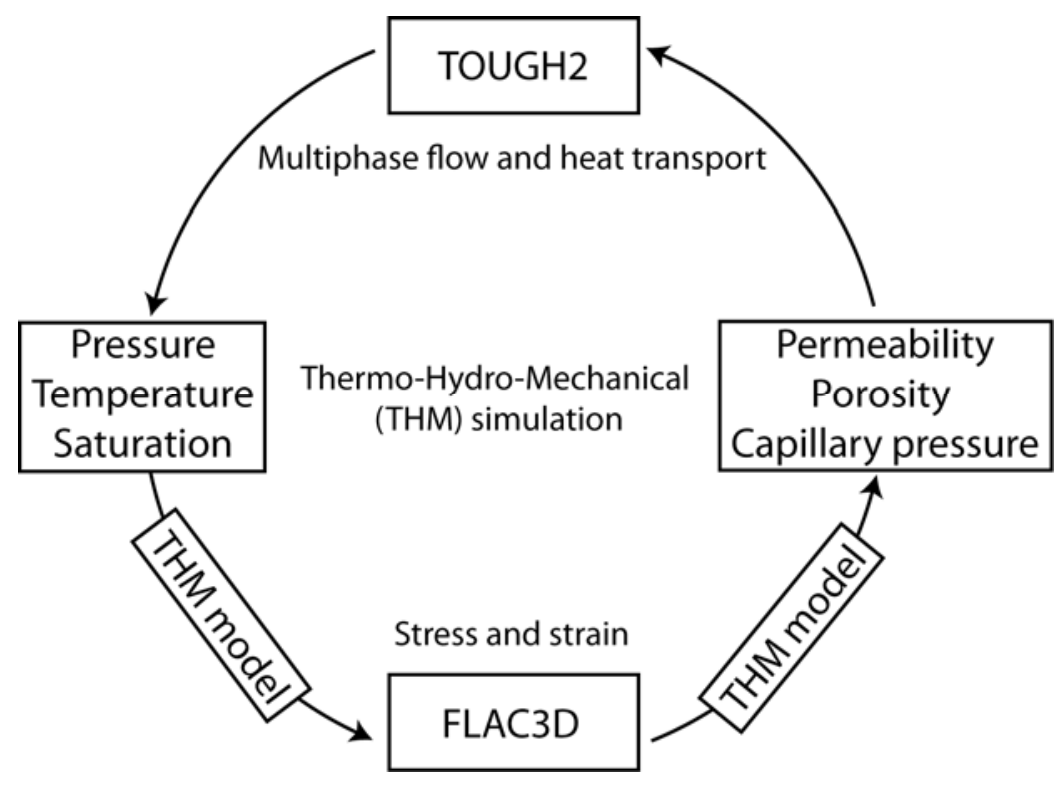

Figure 3. Schematic of linking TOUGH2 and $F L A C^{3 D}$ for coupled Thermo-Hydro-Mechanical (THM) simulation. 

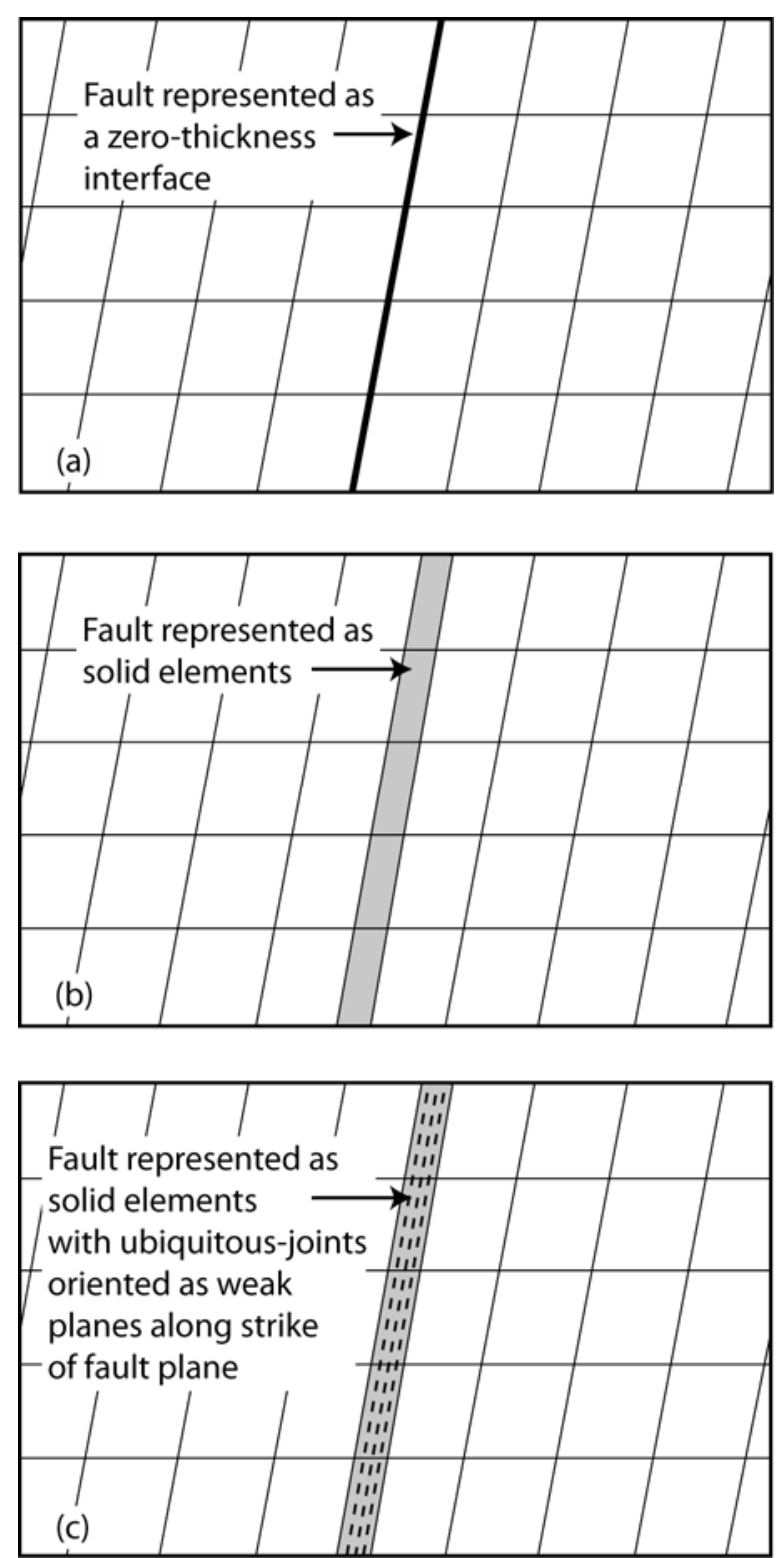

Figure 4. Possible approaches for modeling of hydromechanical behavior of a fault in TOUGH-FLAC. The fault is represented as (a) a zero-thickness interface, (b) solid elements, and (c) solid elements with ubiquitous-joints oriented as weak planes along strike of fault plane. 


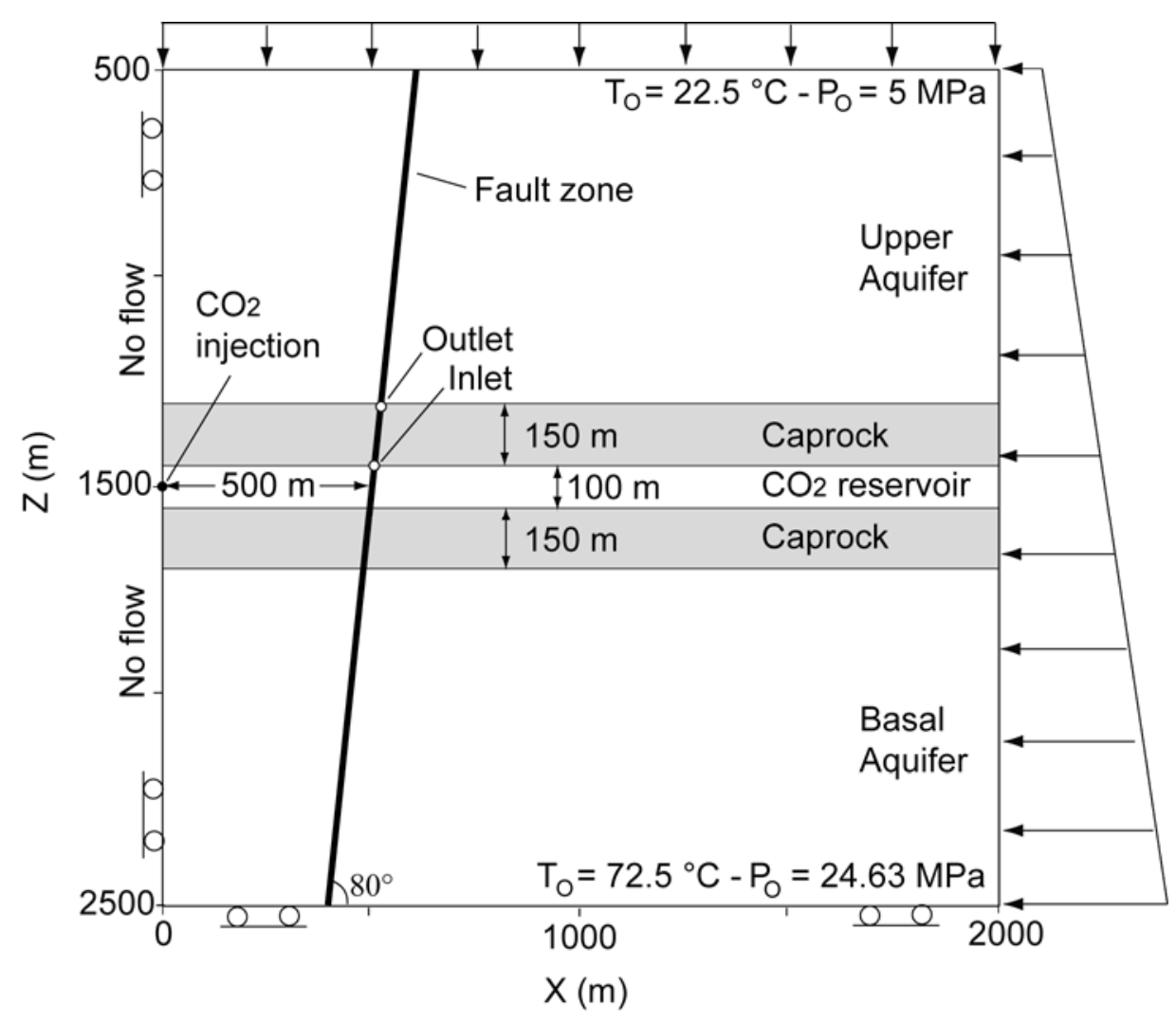

Figure 5. Model geometry for the coupled simulation of $\mathrm{CO}_{2}$ injection and fault slip. 

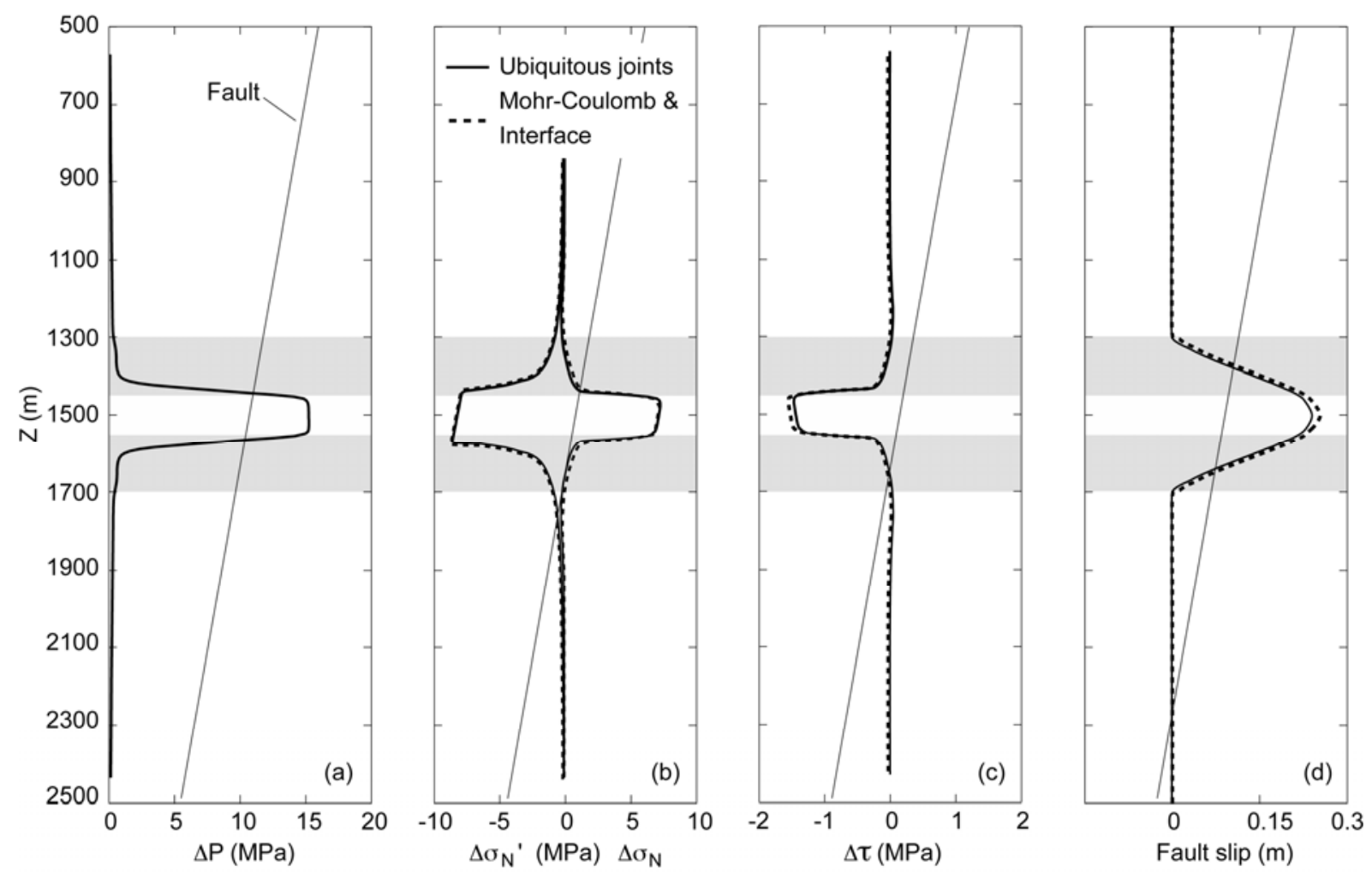

Figure 6. Vertical profiles of change in (a) fluid pressure (b) effective (left-hand side) and total (right-hand side) normal stress, (c) shear stress, and (d) slip along the fault without consideration of shear-slip-induced fault permeability changes. Three fault models are compared: a fault represented as solid elements with ubiquitous-joints as oriented weak planes along the strike of the fault plane (solid line); a fault represented as solid elements with Mohr-Coulomb plasticity (dashed line), and a fault represented as a zero-thickness interface (dashed line). The figure shows how increased fluid pressure in the reservoir causes significant fault slip. 

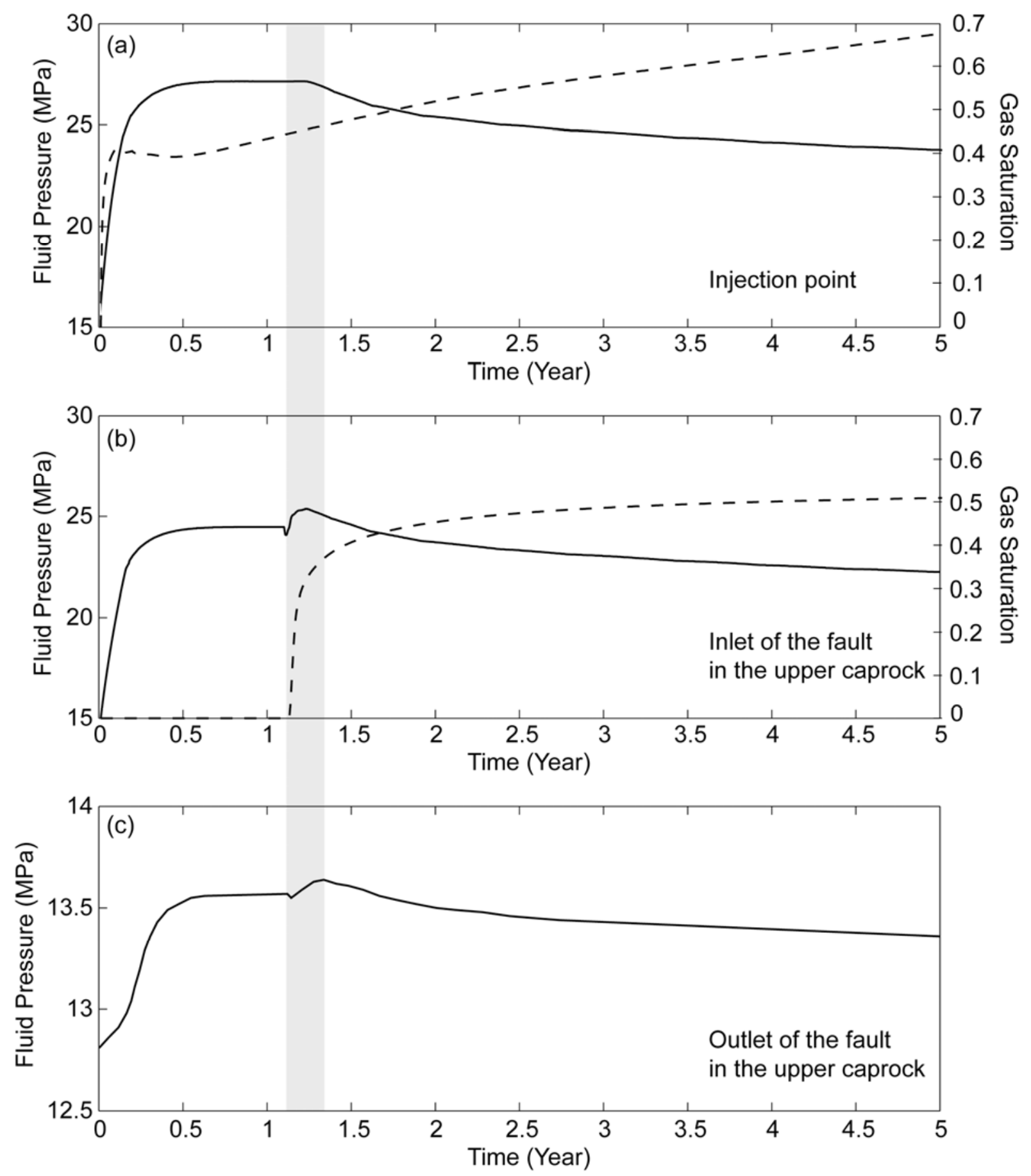

Figure 7. Simulated evolution of fluid pressure (solid line) and $\mathrm{CO}_{2}$ saturation (dashed line) with consideration of shear-slip-induced fault permeability changes: (a) at the injection point, (b) at the inlet of the fault in the upper caprock, and (c) at the outlet the fault in the upper caprock (see location of the inlet and outlet in Figure 5) (Y-axis scales representing fluid pressure are different). The grey zone shows the period during which the injected $\mathrm{CO}_{2^{-}}$ rich fluid reaches and migrates up along the fault. Note that the $\mathrm{CO}_{2}$ rich-fluid reaches the inlet of the fault in the upper caprock after about 1 year of injection, but it does not reach the outlet of the fault in the upper caprock during the 5 years of simulated evolution presented in this figure. 

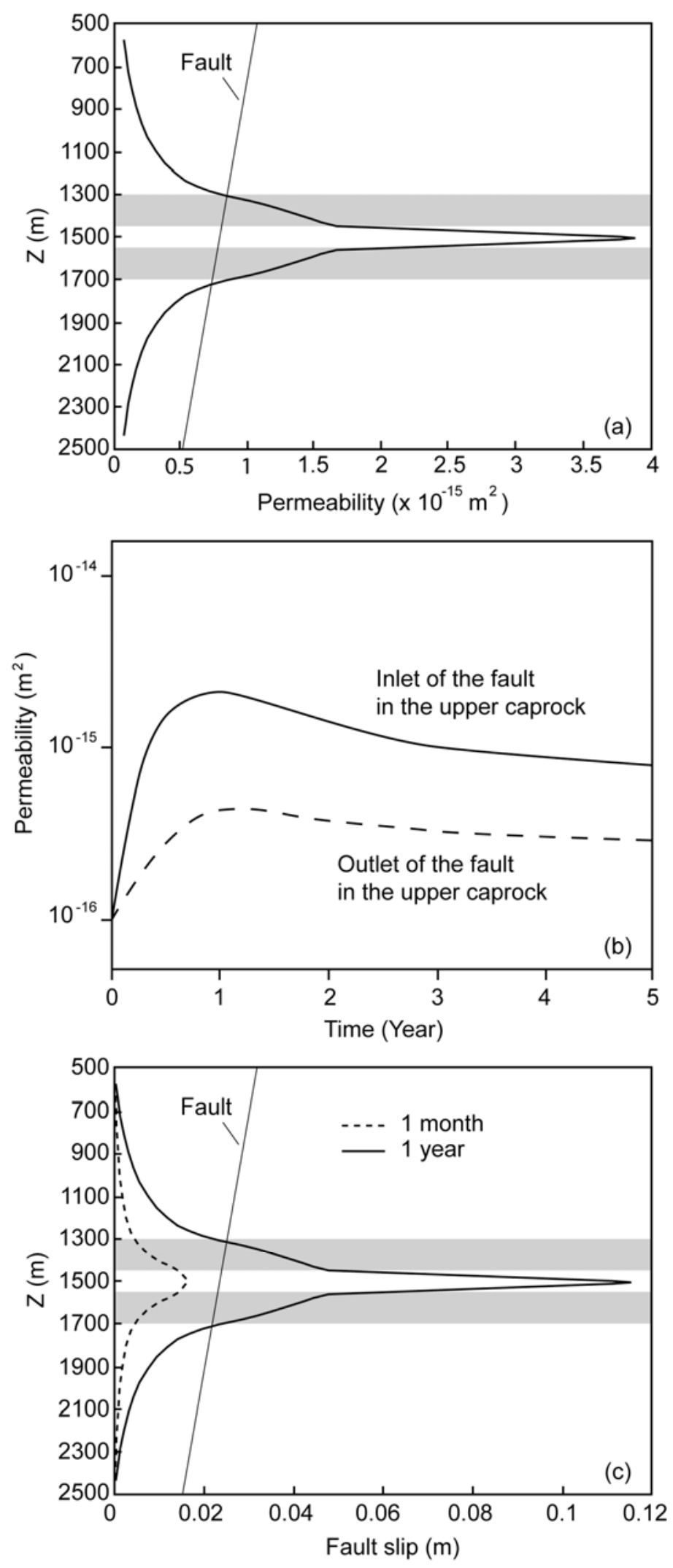

Figure 8. (a) Permeability profile along the fault at 1-year of injection, when the permeability change is the highest; (b) Fault permeability evolution at its inlet and outlet in the upper caprock after 5-years of injection; (c) Vertical profiles of slip along the fault at 1 month (dashed line) and 1 year (solid line) when fluid pressure is the highest. 


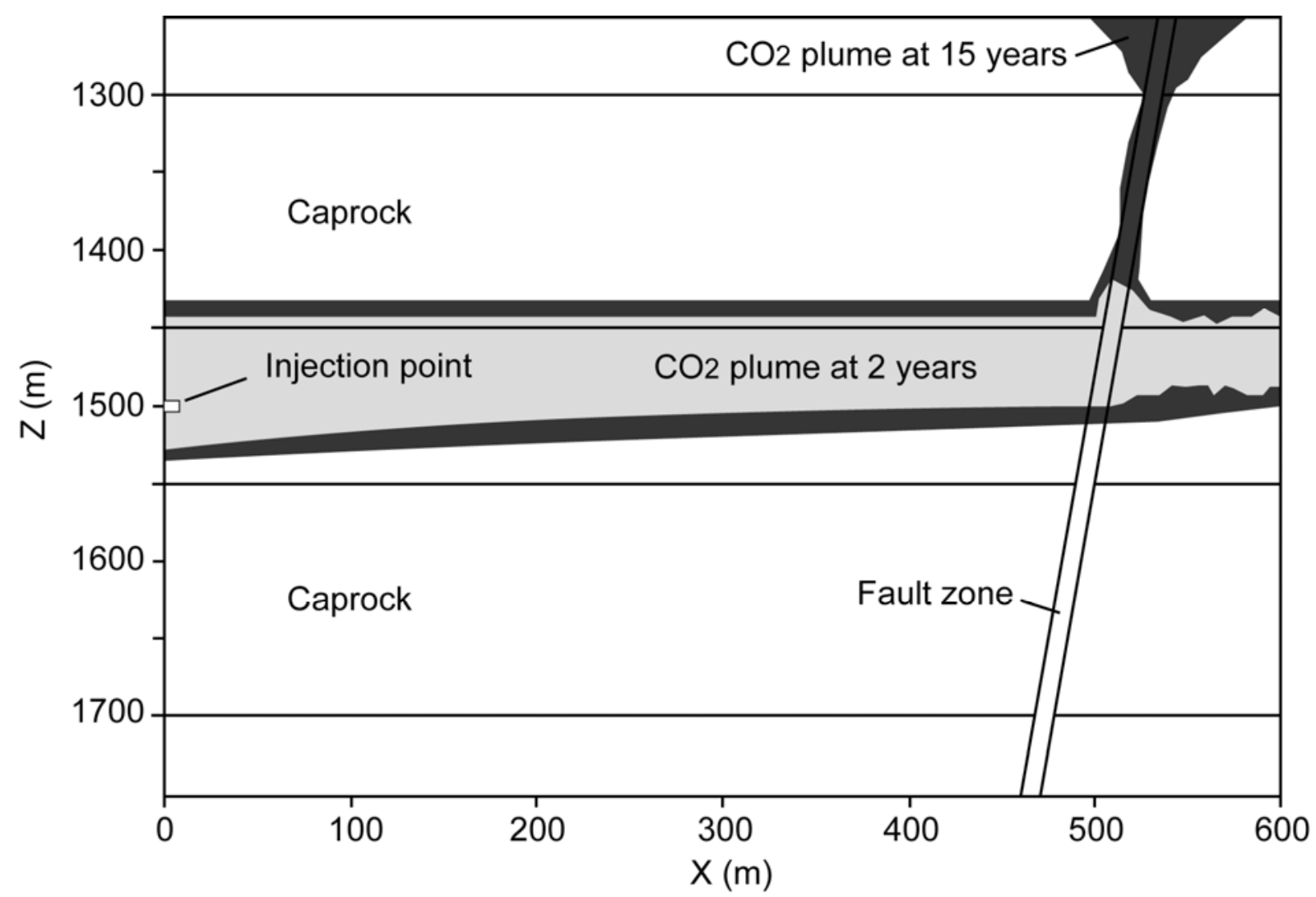

Figure 9. Simulated evolution of $\mathrm{CO}_{2}$-rich phase. The contours indicate how far the $\mathrm{CO}_{2}$-rich fluids have spread as a separate phase after 2-years (grey) and 15-years (black) of injection. 


\section{DISCLAIMER}

This document was prepared as an account of work sponsored by the United States Government. While this document is believed to contain correct information, neither the United States Government nor any agency thereof, nor The Regents of the University of California, nor any of their employees, makes any warranty, express or implied, or assumes any legal responsibility for the accuracy, completeness, or usefulness of any information, apparatus, product, or process disclosed, or represents that its use would not infringe privately owned rights. Reference herein to any specific commercial product, process, or service by its trade name, trademark, manufacturer, or otherwise, does not necessarily constitute or imply its endorsement, recommendation, or favoring by the United States Government or any agency thereof, or The Regents of the University of California. The views and opinions of authors expressed herein do not necessarily state or reflect those of the United States Government or any agency thereof or The Regents of the University of California.

Ernest Orlando Lawrence Berkeley National Laboratory is an equal opportunity employer. 